\title{
MARCHA DE ABSORÇÃO DE ENXOFRE POR PLANTAS DE CANOLA
}

\author{
UPTAKE RATE OF SULPHUR BY CANOLA PLANTS
}

\author{
Marcos Vinícius Ribas MILLÉO ${ }^{1}$ \\ Luiz DONI FILHO ${ }^{2}$
}

\begin{abstract}
RESUMO
Este estudo foi conduzido a campo, na Universidade Estadual de Ponta Grossa (UEPG), em Ponta Grossa, PR, durante os anos de 1994 e 1995. Determinou-se a marcha de absorção de enxofre por plantas de canola em função do estádio de desenvolvimento, em cultivo com e sem irrigação. A demanda por enxofre ocorreu desde os estádios precoces até o desenvolvimento pleno, tendo sido este nutriente requerido quase até o final do ciclo. Pode se verificar que no início da elongação ocorreu a maior necessidade de enxofre e quando as dez primeiras síliquas estavam com desenvolvimento completo, observou-se o maior acúmulo desse elemento na planta. $O$ período compreendido entre a fase de enrosetamento e o início da floração é o mais indicado para a aplicação de enxofre.

Palavras-chave: colza, fertilização com enxofre, absorção de enxofre.
\end{abstract}

\begin{abstract}
This study was conducted in the field at the Universidade Estadual of Ponta Grossa (UEPG), Ponta Grossa, PR, during the 1994 and 1995 years. The uptake rate of sulphur by canola plants was determined as a function of their stage of growth under irrigated and non irrigated cropping. The demand for sulphur took place from the early stages up to full growth, and the nutrient was required nearly until the end of the cycle. It was found that the greatest need for sulphur occurred at the beginning of elongation, and by the time the first ten siliques were fully developed, the greatest accumulation of sulphur in the plant was observed. The period between the rosette stage and the beginning of flowering is the most indicated for the application of sulphur.

Key words: rape, sulphur fertilization, uptake rate of sulphur.
\end{abstract}

\section{INTRODUÇÃO}

\footnotetext{
${ }^{1}$ Engenheiro Agrônomo, Doutor, Universidade Estadual de Ponta Grossa, Departamento de Fitotecnia e Fitossanidade,, Professor Adjunto, Rua Estanislau Piekarski, 22, CEP 84040-110, Ponta Grossa, PR. E-mail: oellim@uepg.br $\equiv$ Autor para correspondência.

2 Engenheiro Agrônomo, Doutor, Universidade Federal do Paraná, Departamento de Fitotecnia e Fitossanitarismo, Professor Adjunto IV, Curitiba, PR. E-mail: doni@agrarias.ufpr.br
} 
A canola é uma oleaginosa de inverno desenvolvida a partir do melhoramento genético da colza, pertence a família das crucíferas e ao gênero Brassica, (Brassica napus L. var. oleifera) e vem tendo sua área de produção ampliada pelo interesse na produção de proteínas e de óleo de alta qualidade. O termo canola é um acrônimo de Canada Oil Low Acid e foi adotado como padrão para indicar baixos teores de ácido erúcico (menos de $2 \%$ do total de ácidos graxos) e glucosinolatos (menos de $30 \mu \mathrm{mol} / \mathrm{g}$ de farelo seco e desengordurado) (ICl Semillas, 1990) [5].

Para o seu cultivo, os solos de textura média bem preparados (sistema convencional) são desejáveis. $\mathrm{O}$ pH deve estar entre 5,5 e 6,0. A faixa térmica considerada ótima para a canola é de 10 a $15^{\circ} \mathrm{C}$ e a soma térmica da cultura, no ciclo, é de 1.040 a $1.100^{\circ} \mathrm{C}$ (ICI Semillas, 1990) [5].

A canola é relativamente tolerante a geadas, necessitando de 450 a $500 \mathrm{~mm}$ de chuva durante o ciclo, sendo que $70 \%$ consumidos durante a floração. A canola é suscetível ao granizo durante a emergência e a maturação.

A restrição hídrica, além do comprometimento fisiológico a que são submetidas as plantas, pode prejudicar a mobilização e a absorção de alguns elementos importantes para a canola como é o caso do enxofre. O enxofre é, provavelmente, o macronutriente menos empregado nas adubações. No entanto muitas culturas importantes exigem-no em quantidades maiores ou iguais ás de fósforo (Mello et al., 1984) [9]. Spencer et al. (1984) [12] relataram que análises feitas nos fertilizantes usados para o cultivo da canola mostraram pequeno ou nenhum teor de enxofre e que, aliado aos baixos níveis do elemento em alguns solos das regiões produtoras, vem causando problemas nas produtividades. A canola retira aproximadamente $45 \mathrm{~kg} \cdot \mathrm{ha}^{-1}$ de enxofre para o seu desenvolvimento (Grant, 1991) [4].

A época ideal para a fertilização com enxofre parece depender também, do tipo de fertilizante, da classe de solo e das condições de pluviometria. Os sulfatos são em geral muito solúveis em água e migram pelo perfil do solo em boas condições de umidade. Nessas condições, aplicações de sulfatos a lanço, na superfície, ou incorporados, se tornam prontamente disponíveis para as plantas. As aplicações mais eficientes têm sido verificadas logo após o estádio de roseta, sem sacrificar a maturação ou a produtividade (Grant e Bailey, 1990) [3].

Malavolta et al. (1984) [8] verificaram que as plantas de canola apresentam resposta positiva no aumento de produtividade quando adubadas com enxofre, desde os estádios iniciais até quase o fim do ciclo. Porém as respostas variaram em função da época de aplicação e em função da dose utilizada. Jansen e Bettany (1984) [6] realizaram experimento com plantas de canola cultivadas em vasos contendo solo deficiente em enxofre, para se comparar a aplicação de enxofre em vários estádios de desenvolvimento (após a semeadura, roseta, formação dos botões e floração) e verificar a melhor época para se suprir a cultura com o elemento. A aplicação de enxofre em todos os estágios de crescimento amenizou prontamente os sintomas de estresse por deficiência, porém os melhores resultados se observaram com aplicações realizadas em estádios mais tardios. A época de aplicação influenciou na quantidade de enxofre absorvido em todos os tratamentos. A aplicação do enxofre no estádio de roseta, floração e particularmente formação dos botões, produziu aumento na absorção de enxofre e na produtividade se comparados com a aplicação na semeadura. No Paraná, durante o período em que se cultiva canola (maio a outubro) é comum a ocorrência de estiagens que podem comprometer o desenvolvimento da cultura. O conhecimento da marcha de absorção do enxofre pela cultura, poderá ser de grande valia na determinação do estádio ideal de necessidade e acúmulo de enxofre pela cultura.

O objetivo do presente trabalho foi de determinar a marcha de absorção de enxofre por plantas de canola em função do estádio de desenvolvimento cultivadas em condições normais de campo e sob irrigação.

\section{METODOLOGIA}

Foram conduzidos dois experimentos a campo, na Fazenda Escola "Capão da Onça", da Universidade Estadual de Ponta Grossa. Os ensaios foram realizados em 1994 e 1995 sendo este último com irrigação.

As áreas onde se conduziu os experimentos (A-01) e (A-10) apresentam um solo LATOSSOLO VERMELHO Distrófico (EMBRAPA, 1999) [2]. A análise de solo, para a amostragem de 0 a $10 \mathrm{~cm}$, apresentou os resultados que se seguem. (A-01): $\mathrm{pH}\left(\mathrm{Ca} \mathrm{Cl} \mathrm{Cl}_{2}\right)=5,50 ; \mathrm{Ca}^{++}=4,10 \mathrm{cmol}_{\mathrm{d}} / \mathrm{dm}^{3} ; \mathrm{Ca}^{++}+$ $\mathrm{Mg}^{++}=7,60 \mathrm{cmol}_{\mathrm{C}} / \mathrm{dm}^{3} ; \mathrm{K}^{+}=0,15 \mathrm{cmol}_{\mathrm{C}} / \mathrm{dm}^{3} ; \mathrm{P}=$ $1,80 \mathrm{mg} / \mathrm{dm}^{3} ; \mathrm{Al}^{+++}=0,0 \mathrm{cmol}_{\mathrm{C}} / \mathrm{dm}^{3} ; \mathrm{C}=18,00 \mathrm{~g} / \mathrm{dm}^{3}$ e $44,0 \%$ de argila, $23,2 \%$ de silte e $32,8 \%$ de areia. (A-10): $\mathrm{pH}(\mathrm{Ca} \mathrm{Cl})=4,80 ; \mathrm{Ca}^{++}=3,90 \mathrm{cmol}_{\mathrm{c}} / \mathrm{dm}^{3}$; $\mathrm{Ca}^{++}+\mathrm{Mg}^{++}=5,40 \mathrm{cmol}_{\mathrm{c}} / \mathrm{dm}^{3} ; \mathrm{K}^{+}=0,11 \mathrm{cmol}_{\mathrm{C}} / \mathrm{dm}^{3}$; $\mathrm{P}=1,2 \mathrm{mg} / \mathrm{dm}^{3} ; \quad \mathrm{Al}^{+++}=0,20 \mathrm{cmol}_{\mathrm{C}} / \mathrm{dm}^{3} ; \mathrm{C}=$ $16,00 \mathrm{~g} / \mathrm{dm}^{3}$ e $46,0 \%$ de argila, $25,4 \%$ de silte e $28,6 \%$ de areia.

O clima da região é classificado como Cfb, segundo Koeppen, com uma precipitação média anual da ordem de $1.422 \mathrm{~mm}$. Foram utilizadas duas áreas experimentais diferentes numa mesma gleba, a área A-01 para o plantio de 1994 e a área A-10 para o de 1995. A semeadura de ambos os ensaios ocorreu no mesmo mês de maio de cada ano. A cultivar utilizada no ensaio foi 'ICIOLA - 41' (Brassica napus L. var. oleifera M.), recomendada pela OCEPAR para a região dos campos gerais. Essa cultivar apresenta ciclo curto (150 dias) e porte baixo $(145 \mathrm{~cm})$ (ICl Semillas, 1990) [5].

O preparo do solo foi feito com uma aração e duas gradagens e para a adubação foram determinados os níveis de $\mathrm{N}, \mathrm{P}$ e $\mathrm{K}$, seguindo-se as recomendações propostas pela OCEPAR, (1994) [11]. A semeadura foi feita manualmente, colocando-se 30 sementes por metro dentro dos 
sulcos espaçados em $30 \mathrm{~cm}$, a uma profundidade de 2 a $3 \mathrm{~cm}$, resultando em uma população de 90 plantas por $\mathrm{m}^{2}$. Em 1995 irrigou-se o ensaio com aspersões de água somando $90 \mathrm{~mm} / \mathrm{mês}$ (exigência mensal da cultura durante o ciclo).

Para a adubação com enxofre utilizou-se o sulfato de amônio com $21,0 \%$ de nitrogênio e $24,2 \%$ de enxofre (Leite, 1986) [7] nas doses e nas épocas de aplicação preestabelecidas. Para o equilíbrio da adubação nitrogenada, estipulada em $90 \mathrm{~kg} \cdot \mathrm{ha}^{-1}$, utilizou-se o nitrato de amônio com 33,0\% de nitrogênio, nas mesmas épocas de aplicação do enxofre. O equilíbrio entre as doses de enxofre e a dose fixa de nitrogênio estabeleceu-se da seguinte forma: a) $0 \mathrm{~kg} \cdot \mathrm{ha}^{-1}$ de enxofre $=272,7 \mathrm{~g}$ de nitrato de amônio por parcela; e b) $100 \mathrm{~kg} \cdot \mathrm{ha}^{-1}$ de enxofre = $421,9 \mathrm{~g}$ de sulfato de amônio $+4,2 \mathrm{~g}$ de nitrato de amônio por parcela.

A colheita foi feita utilizando-se o sistema de corte e enleiramento, quando as sementes encontravam-se com umidade inferior a $35 \%$. As plantas foram cortadas dentro da área útil da parcela e ficaram secando por quatro dias, até apresentarem $9 \%$ de umidade à campo e após foram recolhidas e trilhadas à mão.

Em 1994 foi determinada a marcha de absorção do enxofre bem como a sua concentração na planta nos estádios B-1 (uma folha), B-3 (três folhas), C-2 (início da elongação), $E$ (final da elongação), F-1 (início da floração), G-2 (início da maturação) e G-4 (maturação), utilizando-se plantas tratadas com $100 \mathrm{~kg} \cdot \mathrm{ha}^{-1}$ de enxofre em aplicação parcelada (1/3 na semeadura, 1/3 em B-6 e 1/3 em D-1). Em 1995 foi igualmente estabelecida a marcha de absorção do enxofre e a sua concentração na planta nos estádios B-1 (uma folha), B-2 (duas folhas), B-3 (três folhas), B-4 (quatro folhas), B-5 (cinco folhas), B-6 (seis folhas), B-6 roseta (seis folhas na fase final de roseta), $\mathrm{C}-1$ (início de crescimento vertical), C-2 (internódios visíveis), D-1 (botões florais em formação), D-2 (inflorescência principal desenvolvida), $\mathrm{E}$ (pedúnculos florais se alargam), F-1 (primeiras flores abertas), G-2 (primeiras dez síliquas tem comprimento entre $2 \mathrm{e}$ $4 \mathrm{~cm}$ ), G-3 (primeiras dez síliquas tem comprimento superior a $4 \mathrm{~cm}$ ) e $\mathrm{G}-4$ (as primeiras dez síliquas começam a amadurecer até síliquas e grãos maduros) (Figura 1). Foram utilizadas plantas tratadas com $100 \mathrm{~kg} \cdot \mathrm{ha}^{-1}$ de enxofre em aplicação parcelada (1/3 na semeadura, $1 / 3$ em B-6 e 1/3 em $D-1)$ e o controle, para que se pudesse obter uma comparação da absorção do enxofre em plantas com boa e com baixa disponibilidade de enxofre. Para tais determinações foram coletadas oito plantas inteiras de cada parcela em cada estádio preestabelecido, de onde foram separadas a parte aérea das raízes e as síliquas com os grãos no estádio G-4. As plantas foram postas a secar em estufa com temperatura de $50^{\circ} \mathrm{C}$, até peso constante. As amostras foram enviadas para 0 laboratório para a determinação de enxofre.

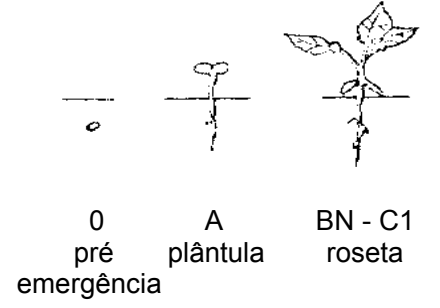

$\begin{array}{llll}0 & 5 & 12 & 50\end{array}$

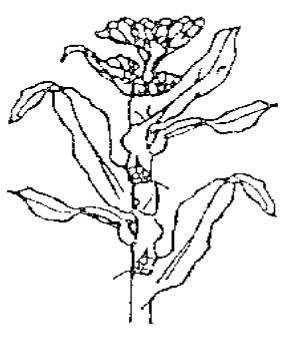

C2 - E elongação

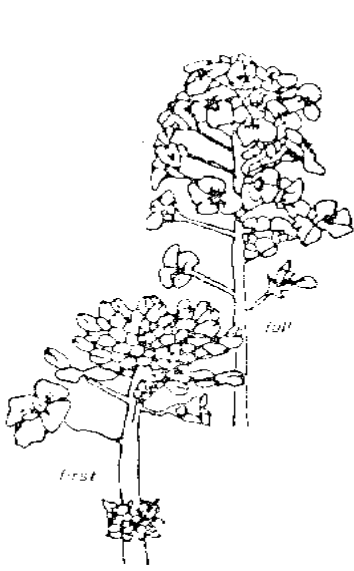

$\mathrm{F} 1-\mathrm{F} 2$

floração

ESTÁDIOS

$\begin{array}{lccc}52 & 70 & 75 & 85\end{array}$

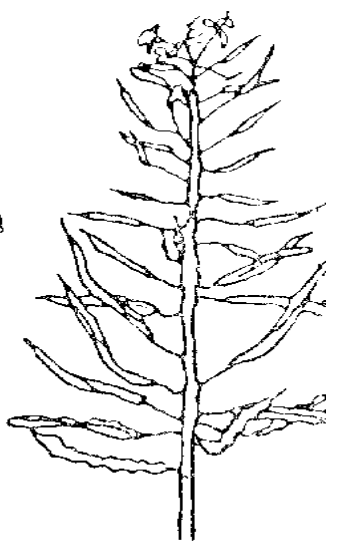

G5

maturação

FIGURA 1 - Estádios e dias de desenvolvimento da cultura da canola (Brassica napus L. var. oleífera) (Thomas, 1984)[13]

\section{RESULTADOS E DISCUSSÃO}

Os resultados permitiram verificar que em 1994, de acordo com a Figura 2, que a partir do estádio B-3 (três folhas) as plantas apresentaram aumento na concentração de enxofre e, a partir de C-2 (início da elongação), iniciou-se o processo de crescimento vertical, onde aumentaram as 
ramificações laterais e surgiram os primeiros botões florais. A concentração de enxofre permaneceu constante até F-1 (início da floração) e a partir daí ocorreu o máximo acúmulo na fase de floração e formação de síliquas e grãos, provavelmente, em função do rápido crescimento vegetativo das plantas, juntamente com a formação das flores, síliquas e grãos. A partir desse estádio constatou-se a menor quantidade do elemento na matéria seca pela própria senescência da planta, queda natural de folhas e aumento da concentração de enxofre nas síliquas e grãos.

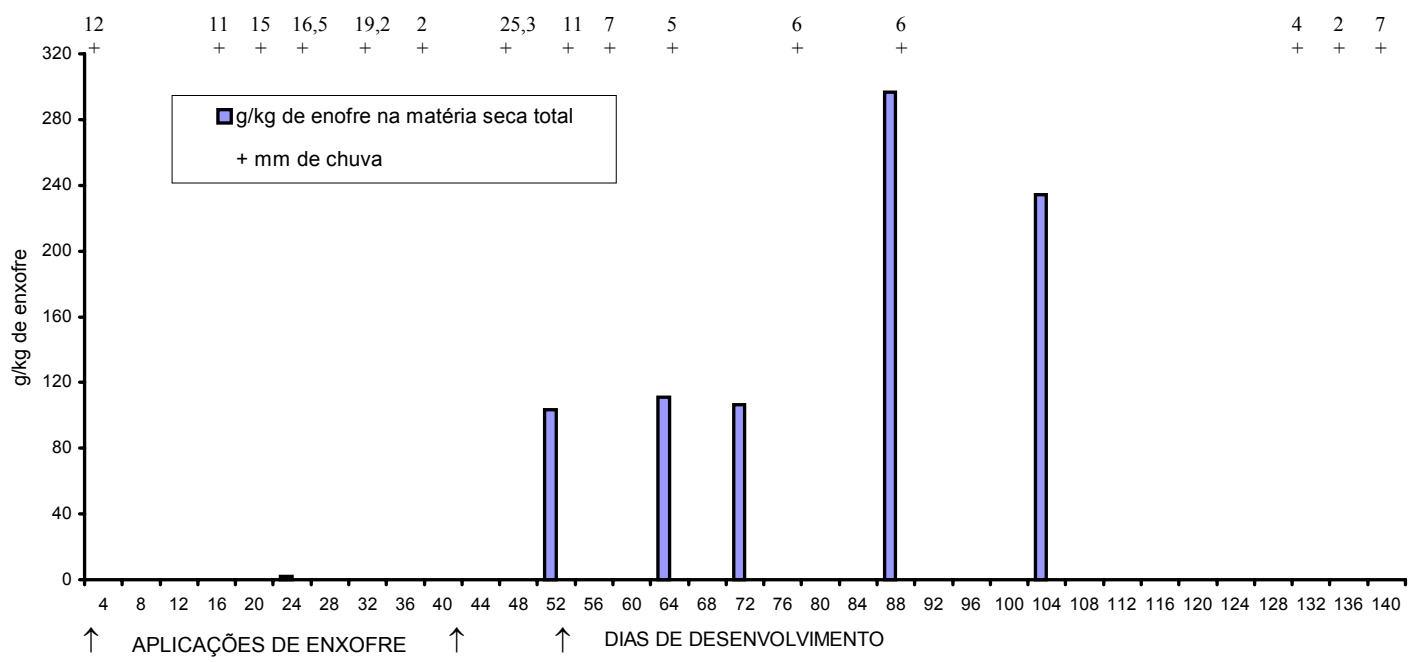

FIGURA 2 - Marcha de absorção de enxofre na cultura da Canola (Brassica napus L. var. oleifera) cultivar 'ICIOLA-41', realizada com a dose de $100 \mathrm{~kg}$ ha $^{-1}$ em aplicação parcelada (1/3 na semeadura, $1 / 3$ b-6 e 1/3 d-1) no ano agrícola de 1994, UEPG, Ponta Grossa, PR

Em 1995 sob condições de irrigação, permitindo uma comparação entre a absorção e acúmulo do elemento em condições de disponibilidade de água e de déficit hídrico no solo, observou-se nas plantas tratadas com $100 \mathrm{~kg} \mathrm{ha}^{-1} \mathrm{de}$ enxofre (Figura 3) em aplicação parcelada (1/3 na semeadura, $1 / 3$ em B-6 e 1/3 em D-1), que a partir do estádio B-3 (três folhas verdadeiras) as plantas tiveram aumento na concentração de enxofre, em B6 (seis folhas) e B-6R (formação da roseta), observou-se grande acúmulo em relação aos estádios anteriores, passando de $7,464 \mathrm{~g} / \mathrm{kg}$ em B-5 (cinco folhas) para $33,533 \mathrm{~g} / \mathrm{kg}$ em B-6R. A partir de C-2 (início da elongação) iniciou-se o processo de crescimento vertical, com aumento das ramificações laterais e surgimento dos primeiros botões florais. As plantas apresentaram acúmulos crescentes de enxofre e a concentração sofreu pequenas flutuações nos estádios D-2 (elongação, com a inflorescência principal visível) e $\mathrm{F}-1$ (início da floração). A partir de G-3 (dez primeiras síliquas tem comprimento superior a $4 \mathrm{~cm}$ ) verificou-se redução na concentração do elemento na matéria seca da parte aérea, pela própria senescência da planta e por efeito de diluição, mas em relação ao peso total (parte aérea, raiz, síliquas e grãos) a concentração permaneceu sempre crescente.

Para as plantas tratadas com $0 \mathrm{~kg} \cdot \mathrm{ha}^{-1}$ de enxofre, observou-se (Figura 4) que a partir de B-4 (quatro folhas verdadeiras) as plantas apresentaram concentrações bem menores do que em relação a dose de $100 \mathrm{~kg} \cdot \mathrm{ha}^{-1}$ de enxofre. Formam-se as ramificações laterais, surgem os primeiros botões florais e até F-1 (início da floração) o acúmulo se mantém crescente, porém, em G-2 (dez primeiras síliquas têm comprimento entre 2 e $4 \mathrm{~cm}$ ), G-3 (dez primeiras síliquas têm comprimento superior a $4 \mathrm{~cm}$ ) e G-4 (maturação das dez primeiras síliquas), a concentração do enxofre na matéria seca da parte aérea se mostrou menor. Em relação ao peso total (parte aérea, raiz, síliquas e grãos) a concentração permaneceu crescente.

Pode se observar que o maior acúmulo de enxofre ocorre em estádios mais afastados da semeadura, principalmente, após o estádio B-6, indicando que o crescimento inicial é relativamente lento, mas quando a planta inicia a elongação e a formação dos componentes da produção (estatura, ramificações, botões florais, flores e síliquas) verifica-se intenso acúmulo sinalizando a sua utilização pela planta. Isso responde algumas observações feitas de que as melhores épocas para a aplicação de enxofre ocorrem em estádios mais tardios e confirma os resultados semelhantes encontrados por Casarini et al. (1984) [1]; Malavolta et al. (1984) [8]; Grant e Bailey (1990) [3]; Nuttall e Ukrainetz (1991) [10], que verificaram que a melhor época para a aplicação de enxofre vai do estádio C-2 (início da elongação), (Figura 1), até F-1 (início da floração). Aplicações posteriores podem comprometer a produtividade pela ausência do elemento em períodos importantes do crescimento da planta, como a formação dos componentes da produção. 


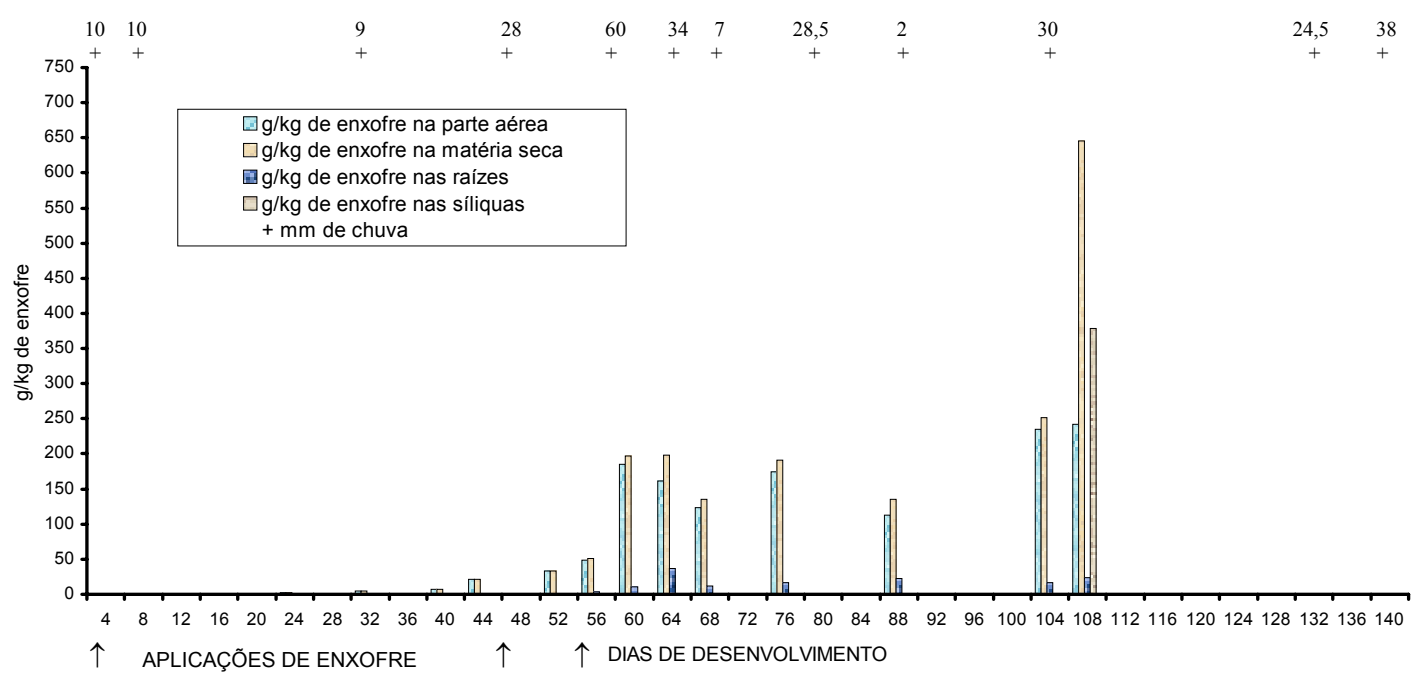

FIGURA 3 - Marcha de absorção de enxofre na canola (Brassica napus L. var. oleifera) cultivar 'ICIOLA-41', realizada com a dose de $100 \mathrm{~kg} \cdot \mathrm{ha}^{-1}$ em aplicação parcelada (1/3 na semeadura, 1/3 b-6 e 1/3 d-1) no ano agrícola de 1995, UEPG, Ponta Grossa, PR

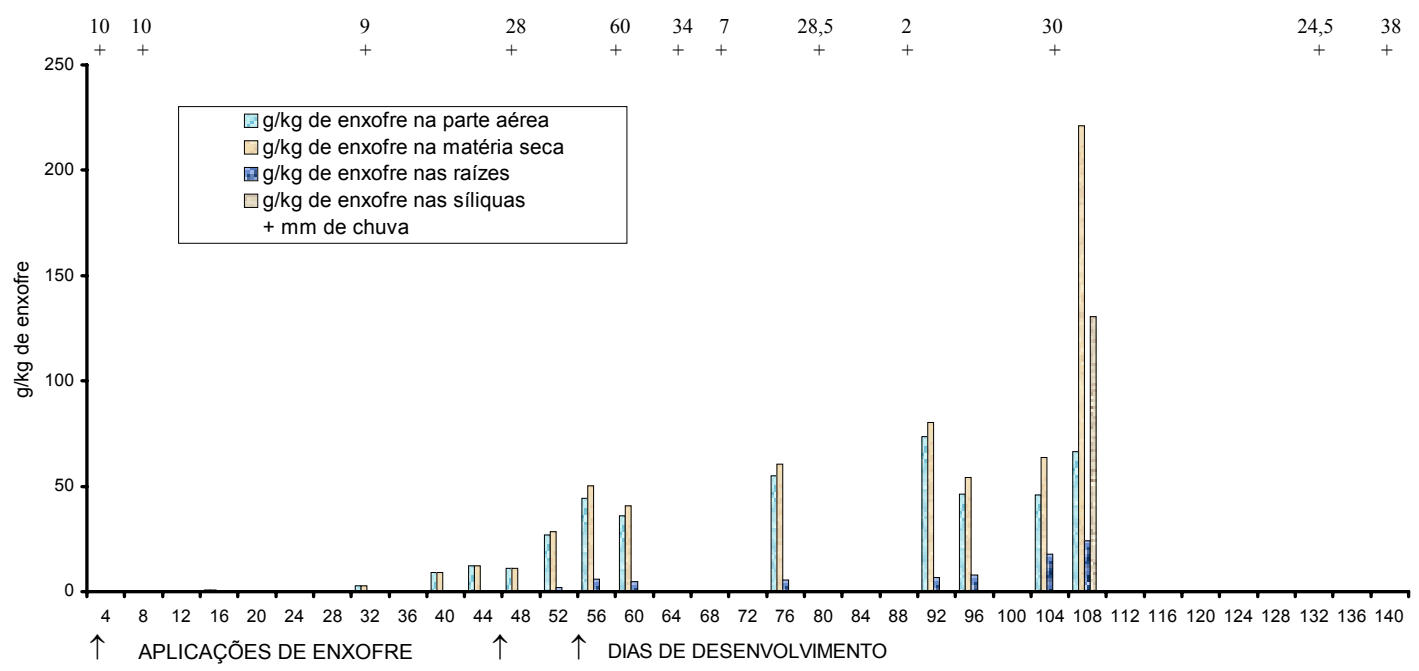

FIGURA 4 - Marcha de absorção de enxofre na canola (Brassica napus L. var. oleifera) cultivar 'ICIOLA-41', realizada com a dose de $0 \mathrm{~kg} \cdot \mathrm{ha}^{-1}$, no ano agrícola de 1994, UEPG, Ponta Grossa, PR

\section{CONCLUSÕES}

1) A demanda pelo enxofre ocorre desde os estádios mais precoces (B-N) até os mais avançados de desenvolvimento, sendo utilizado quase até o fim do ciclo.

2) O estádio C-2, quando os internódios começam a ficar visíveis e se inicia a elongação, é o momento de máxima necessidade de enxofre.

3) O estádio G-3, quando as dez primeiras síliquas atingem comprimento superior a $4 \mathrm{~cm}$ é o momento de maior acúmulo do enxofre na planta.
4) O período que vai do início do estádio de roseta (B-6) ao início da floração (F-1) é o momento quando se deve aplicar o enxofre.

5) Os estádios C-2 e G-3 são os de máxima necessidade de enxofre.

6) A ausência de irrigação (Experimento de 1994) evidencia menores concentrações de enxofre, menor estatura de plantas e menor quantidade de matéria seca.

\section{REFERÊNCIAS}


[1] CASARINI, M. A. G. S.; HAAG, P. H. Absorção, concentração e exportação de nutrientes por duas linhagens de colza (Brassica napus) em função da idade. I - macronutrientes. Piracicaba:: ESALQ, 1984, 84 p. (Boletim Técnico n. 41)

[2] EMBRAPA. Sistema brasileiro de classificação de solos. Brasília: EMBRAPA, 1999. 412 p.

[3] GRANT, C. A.; BAILEY, L. D. Fertility management in canola production. In: INTERNATIONAL CANOLA CONFERENCE, 1990, Atlanta. Summary. Atlanta:: Potash and Phosphate Institute, 1990. 303 p.

[4] GRANT, C. A. Sulphur requirements of canola. Sulphur in Agriculture, Manitoba, v.15, p. 3-6, 1991.

[5] ICI SEMILLAS. Iciola canola hibrida. Buenos Aires: ICI Semillas, 1990. 39 p. (Boletín Técnico n. 8).

[6] JANZEN, H. H.; BETTANY, J. R. Sulfur nutrition of rapeseed II. effect of time of sulphur application. Soill Science Society of America Journal, Madison, v.48, n.1, p. 107-112, 1984

[7] LEITE, J. P. Tabelas de conversão de fertilizantes. 6 ed. São Paulo: Nobel, 1986. 184 p.

[8] MALAVOLTA, E.; VITTI, G. C.; FORNASIERI FILHO, D.; CARVALHO, J. G.; MALAVOLTA, M. L.; ZAMBELLO, F. C. Efeitos de doses e fontes de enxofre em culturas de interesse econômico. II colza (Brassica napus L. var. oleifera). São Paulo:
Centro Nacional de Pesquisa e Promoção do Sulfato de Amônio, 1984. 60 p. (Boletim Técnico n. 3).

[9] MELLO, F. A. F.; BRASIL SOBRINHO, M. O. C. ARZOLLA, S.; SILVEIRA, R. I.; COBRA NETTO, A.; KIEHL, J. C. Fertilidade do Solo. 2. ed. São Paulo: Nobel, $1984,400 \mathrm{p}$.

[10]NUTTALL, W. F.; UKRAINETZ, $H$. The effect of time of $S$ application on yield and sulphur uptake of canola. commun. Soil Science Plant, Saskatchewan, v.22, n.3-4, p. 269-281, 1991.

[11]OCEPAR - ORGANIZAÇÃO DAS COOPERATIVAS DO ESTADO DO PARANÁ. Recomendações técnicas para o cultivo de canola no Estado do Paraná em 1994. Cascavel: OCEPAR, 1994. 125 p. (Circular 23).

[12]SPENCER, K.; FRENEY, J. R.; JONES, M. B. A preliminary testing of plant analysis procedures for the assessment of the sulphur status of oilseed rape. Australian Journal of Agricultural Research, Canberra, v.35, n.2, p. 163-175, 1984.

[13]THOMAS, P. Canola growers manual: grow with canola. Winnipeg: Canola Council of Canada, 1984. 1424 p. (Manual).

Recebido para publicação em 19 SET 1999 [SA 008/1999]

Aceito para publicação em 24 ABR 2001 